\title{
A Qualitative Analysis of Factors Influencing Household Water Treatment Practices Among Consumers of Self-Supplied Water in Rural Ethiopia
}

This article was published in the following Dove Press journal: Risk Management and Healthcare Policy

\author{
Aiggan Tamene $\mathbb{C}$ \\ Environmental Health Unit, Department \\ of Public Health, College of Medicine and \\ Health Sciences, Wachemo University, \\ Hossana, Ethiopia
}

Background: The health of a community depends greatly on the availability of sufficient and clean water. Rural households relying on self-supplied drinking water must take full responsibility for the treatment of their drinking water. Globally, not many inquiries appear to have been carried out to satisfactorily inform us regarding how and why improvements in behavior related to water treatment occur in some selected individuals and not in others. Related investigations in Ethiopia are even fewer.

Methods: In the rural Aleta Wondo district of Ethiopia, a total of fifteen focus group discussions were conducted with community members. Similarly, ten key informant interviews were conducted with officers responsible for organizing water and hygiene programs. To gather data for this study, two qualitative data collection methods, viz., key informant interviews and focus group discussions, were used. Open code software 4.03 was used for thematic analysis.

Results: Factors influencing household water treatment practices were categorized into individual-level factors (eg cognitive factors, emotional factors), household-level factors (household means and decision-making balance), community-level factors (the value that is given for water quality and Public resources) and, environment and context-related factors (access to products and reliance on external sources).

Conclusion: Household water treatment practice has a range of multilevel influences. Beyond the model of providing ongoing safe water education by health extension workers, potential initiatives could be improved by community mobilization activities that include community leaders, women's groups, etc., in promoting water treatment at community engagements. Also, the results of the present study indicate that it could be beneficial to provide health extension staff with additional training to improve their ability to encourage community members across, a wide range of user types or levels of readiness, to treat their water.

Keywords: self-supplied, rural Ethiopia, water treatment

\section{Introduction}

A community's wellbeing depends greatly on the availability of adequate and clean water. ${ }^{1}$ Water is therefore primarily important for life, health, and human dignity. In addition to the public health benefits, all persons have the right to healthy and adequate access to water for drinking, cooking, personal and domestic hygiene, ${ }^{2,3}$ and because of the potential for serious and widespread outbreaks of waterborne diseases, controlling the risk of microbiological contamination of drinking water is of great importance. ${ }^{2}$

Several outbreaks of illnesses have resulted from microbiological drinking water pollution, including in Ethiopia. ${ }^{4}$ In Ethiopia, a legally binding drinking water quality standard was established by the National Quality and Standards Authority 
in $2001 .^{5}$ This Act mandates drinking water suppliers to monitor drinking water; enforce a water protection plan, and take all practical measures to ensure safe water supply.

Despite these robust set of standards, a subset of the population remains for whom no such drinking water quality and safety legislation exists. Rural households relying on self-supplied drinking water, such as bores (also referred to as 'wells') and rainwater must take full responsibility for the development, including investment in the construction, upgrading, and upkeep of their water sources, lifting devices, storage facilities, and treatment of their drinking water. ${ }^{6}$

Indeed, research suggests that rural Ethiopians may be at greater risk of contracting a waterborne disease than their urban counterparts. ${ }^{7,8}$ Rural Ethiopia's access to clean water sources is the lowest in Sub-Saharan Africa, with rural households responsible for $57 \%$ of the unimproved water supply. Just $21.8 \%$ of rural households have access to drinking water from piped supply; protected dug well and protected springs account for $7 \%$ and $13.9 \%$ respectively. ${ }^{9}$

In the Aleta Wondo district of Sidama Region, rural water services are provided through a mix of self-, community- and utility-management models. The self-supplied water sources are situated closer to the house and mostly tend to be used for productive activities such as vegetable husbandry, small-scale irrigation, livestock watering, as well as drinking, and other domestic uses. The main concern related to this approach is the safety of drinking water. ${ }^{10}$ This was also true in the study area. Domestic wells were found to be at a high risk of contamination with total coli forms in a recent survey of the bacteriologic quality of drinking water in the region. In most cases, bacterial contamination of drinking water was substantially associated with the presence of animal faeces and insufficient fencing around water sources. ${ }^{11}$

According to the World Health Organization (WHO), to achieve universal access to safe water for households, the use of household water treatment technologies is necessary where piped water systems are not feasible and where people rely on water supplies that may be contaminated. ${ }^{12}$ Similarly, the Ethiopian Ministry of Health recommends the use of different point-of-use water treatment options, including ultraviolet disinfection, chemical disinfection, membrane ultra-filtration, flocculation disinfection, etc. ${ }^{13}$

Ethiopia's Health Transition Plan stipulates that it is planned to achieve $35 \%$ coverage of water treatment methods in households by the end of $2020 .{ }^{13}$ However, the practice of point-of-use water treatment methods remains low. ${ }^{9}$ Although water treatment programs at the point of use have the potential to reduce diarrheal diseases by as much as $29-44 \%,{ }^{14,15}$ only $7.9 \%$ of the rural population uses some kind of household water treatment, according to the 2016 Ethiopian Demographic Health Survey. ${ }^{9}$

In rural Ethiopia, household water quality levels have been documented both at the national and international levels. In the context of point-of-use approaches, however, little is understood about how and why improvements in behavior related to water treatment occur in some selected individuals and not in others. For developing more successful safe water behavioural interventions, a more complete understanding of factors influencing water treatment decisions, including whether, how, and when drinking water is treated, is necessary. It is against this background that this article aims to explore the factors influencing household water treatment practices among consumers of self-supplied water in rural Ethiopia.

\section{Methods and Materials}

The study was conducted in the Aleta Wondo district of Sidama Region, one of Ethiopia's eleven federal states, from April to May 2020. Aleta Wondo district, located 333 kilometres southeast of Addis Ababa, the national capital, is subdivided into 17 rural and 4 urban Kebeles (the lowest administrative unit in Ethiopia). The district has a total population of $212,459 .{ }^{16}$ The Rural Health Extension Program (HEP) was implemented in the district fifteen years ago with a focus on improving household water, hygiene, and sanitation services. ${ }^{17}$ Since then, each Kebele in the district has been assigned two individuals from the program, so-called health extension workers (HEWs) that provide door-to-door education.

Using lottery sampling, five, (Wicho, Hondowa, DongoraElemate, Ginbanto, Buda), of the 17 rural Kebeles were picked at random. This study's design is qualitative, and thus qualitative methodologies were used for data gathering, ie semi-structured key informant interviews (KIIs) and focus group discussions (FGDs). Purposive sampling based upon identification of households in areas where family wells and rain harvesting are known to be used for drinking, rope pumps were installed and where community-led wells (hand pumps) were functioning was used. Significant attempts were made to include all known areas with relevant self-supplied water sources in the selected Kebeles. 
In the present study, two sets of participants were identified and used, to examine the factors affecting the adoption and utilization of point-of-use water treatment technologies at the household and community level; male and female household heads were recruited from the selected Kebeles in consultation with local civic leaders and HEWs. Although women are often the primary implementers of household water, sanitation, and hygiene services, it has previously been reported that most women in the developing world do not have a voice equal to their partners regarding spending. ${ }^{18}$ Both men and women were thus included in the FGDs. Also, to investigate the societal factors that influence the adoption and use of point-of-use water treatment options, Kebele Water Sanitation and Hygiene program coordinators and Health Extension Workers were used as key Informants.

The principal investigator, three data collectors, and a veteran supervisor were part of the study team. The research sample size was driven by the number of Focus Groups and Key Informant Interviews conducted. Until the data reached saturation, a point at which repeated trends were visible in the narratives of the participants, a total of 15 FGDs were conducted in the selected rural Kebeles. Each group had 7 members and public health workers used purposeful screening to invite respondents to the FGDs. Five of the focus groups included all-female community members, another five included all-male community members, and a mixed group of local leaders were included in the last five groups.

In addition to the FGDs, in each Kebele; two key informant interviews were conducted. Interview participants were chosen from the Kebele WASH Coordination Office and Health Extension Program (HEP) office. Table 1 describes the numbers of interviews and focus groups conducted, transcribed, and ultimately included in the analysis by respondent category.
Following an in-depth analysis of relevant literature, the semi-structured KII and FGD guides used for data collection were developed by the research team. The data collection guides focused on the participants' understanding and perceptions of household water treatment choices plus the motivations for and barriers to the adoption and continued use of household water treatment technologies (Additional file 1). Every conversation and interview with the participants in the study was audio-recorded with the assent of the study participants.

For data analysis, Open code software 4.03 was used, which followed a thematic outline. The data obtained in Amharic (the official language of Ethiopia) was first transcribed verbatim and then translated into English. Subsequently, the author examined the transcripts several times to become more familiar with the material ahead of the sorting, coding, and theme identification process. Preliminary descriptive codes were based on data immersion with the transcript from each group (females, males, civic leaders, and key informants). First, a selection of transcripts was read line by line during coding, and codes were added to each passage illustrating the basic meaning of the data within. The researcher compared the codes after five transcripts were coded to establish an initial thematic structure. The thematic framework was refined with five more transcripts, ensuring that the framework encompassed all the data in the transcripts applicable to the research question. The thematic framework was updated until the research team was confident that it fitted the data. Once developed, the framework was extended to all transcripts.

\section{Result}

\section{Awareness of Water Treatment Methods}

The study participants' knowledge of household water treatment options was one important piece of information

Table I Number of Interviews and Focus Groups by Respondent Category

\begin{tabular}{|c|c|c|c|}
\hline Respondent Category & Total Conducted & Total Transcribed & Total Analyzed \\
\hline \multicolumn{4}{|c|}{ Focus group discussions } \\
\hline All-male FGDs & 5 FGDs (35 participants total) & 5 FGDs (35 participants total) & 5 FGDs (35 participants total) \\
\hline All-female FGDs & 5 FGDs (35 participants total) & 5 FGDs (35 participants total) & 5 FGDs (35 participants total) \\
\hline Mixed (male/female) & 5 FGDs (35 participants total) & 5 FGDs (35 participants total) & 5 FGDs (35 participants total) \\
\hline \multicolumn{4}{|c|}{ Key informant interviews } \\
\hline Kebele WASH Officers & 5 interviews conducted & 4 transcribed $^{a}$ & 4 analyzed \\
\hline Health extension officer & 6 interviews conducted & 6 transcribed & 6 analyzed \\
\hline
\end{tabular}

Note: ${ }^{a}$ One interview could not be transcribed because recordings were of poor sound quality due to background noise. 
sought in this study. Awareness of at least one household water treatment option among the participants appears to be a nearly universal phenomenon (Table 2). Evidence from the study participants confirms this observation

We can treat water by boiling it, by using our clothes for filtering, we can use Wuha Agar (chlorine solution), we can use the sun as well; these are the things we can use if we want to. (FGD 6, Male 45 years old)

... For example, we can use sand filters to treat water. (FGD 11, Female 27years old)

Table 2 Frequency Distribution of Number of Household Water Treatment Options Mentioned by Study Participants During Focus Group Discussions

\begin{tabular}{|l|l|l|l|}
\hline $\begin{array}{l}\text { Number of Water } \\
\text { Treatment Options } \\
\text { Mentioned }\end{array}$ & Frequency & Percentage & $\begin{array}{l}\text { Cumulative } \\
\text { Percentage }\end{array}$ \\
\hline 0 & 3 & $2.85 \%$ & $2.85 \%$ \\
1 & 32 & $30.45 \%$ & $33.25 \%$ \\
2 & 40 & $38.0 \%$ & $71.25 \%$ \\
3 & 23 & $21.90 \%$ & $93.2 \%$ \\
$>\underline{4}$ & 7 & $6.8 \%$ & $100 \%$ \\
\hline
\end{tabular}

\section{Factors Influencing Water Treatment}

In the rural district of Aleta Wondo, the consumers of selfsupplied water understood the quality of drinking water in many respects, sometimes referring to it in terms of health and other times referring to it in terms of aesthetic features or contamination.

For me, the first measure of water quality is whether I can drink it and not get ill. (FGD 1, Female 24 years old)

If I can't see anything that floats or foreign bodies when I look at my glass, I would consider myself as drinking clean water. (FGD 3, Male 40 years old)

These definitions serve to introduce four key themes identified during the analysis of the data collected from the FGDs and KIIs. These include Individual-level factors, Household-level factors, Community-level factors, and Environment and context-related factors (Table 3).

\section{Individual-Level Factors Cognitive Factors}

In the present study, many individual-level barriers concerning household water treatment practices were discussed during the focus groups and interviews. A general lack of knowledge of the causes of water-borne diseases

Table 3 Thematic Framework

\begin{tabular}{|c|c|c|}
\hline Main Themes & Subthemes (Category) & Subcategories \\
\hline \multirow[t]{6}{*}{ Individual level factors } & Cognitive factors & Awareness of the causes of water-borne diseases \\
\hline & & Attitudes concerning practice and product \\
\hline & & Perceptions of severity from untreated water \\
\hline & & Subjective Norms and Support for treatment practices \\
\hline & & Self-image \\
\hline & Emotional Elements & $\begin{array}{l}\text { Aesthetics (appearance, smell, and taste) } \\
\text { Distrust of local officials }\end{array}$ \\
\hline \multirow[t]{2}{*}{ House hold level factors } & Household means & Affordability of treatment technologies and competing priorities \\
\hline & Decision-making balance & Women's lack of control over household spending \\
\hline \multirow[t]{2}{*}{ Community level factors } & $\begin{array}{l}\text { The value that is given for } \\
\text { water quality }\end{array}$ & Community priority for water quality \\
\hline & $\begin{array}{l}\text { Public actions and } \\
\text { resources }\end{array}$ & $\begin{array}{l}\text { Presence of social organizations such as health committees, health clubs, and mothers } \\
\text { clubs }\end{array}$ \\
\hline \multirow[t]{2}{*}{$\begin{array}{l}\text { Environment and context } \\
\text { related factors }\end{array}$} & Access to products & $\begin{array}{l}\text { Trouble free access to products for the treatment } \\
\text { Geographic setting and Living nearer to the capital and closer to bus and open road } \\
\text { services }\end{array}$ \\
\hline & $\begin{array}{l}\text { Reliance on external } \\
\text { sources }\end{array}$ & $\begin{array}{l}\text { Free water treatment technologies provided by Non-governmental Organizations and } \\
\text { Free samples distributed by the local health centers }\end{array}$ \\
\hline
\end{tabular}


was described as a major barrier to household water treatment by many of the participants.

The majority of people here often assume that diarrhoea in infants and young children is unavoidable and that early diarrhoea must be experienced by newborns as a sign of survival. (FGD 3, Female 40 years old)

The same respondent also described further the rationale that some early adaptors of household water treatment technologies followed for discontinuing the practice.

Among caregivers who are aware of the connection between water and diarrhoea, one of the most common explanations for not purifying drinking water was that their children were old enough to drink untreated water. By the time their child was two years old, many of my neighbours had either stopped or planned to stop boiling water.

Similarly, key informants also identified illiteracy and generally low levels of education as a challenge for individuals to recognize the value of water treatment and other safe water practices.

The main problem in this area is that communication is difficult as the number of literate individuals is very limited, and understanding something takes a lot of repetition.

That is a big issue. (35 years old Male, Health extension worker)

Culture, beliefs, and values too became apparent as a major impediment to treating water in the household. A repeated allusion from the key informants was that some had a negative attitude towards treating water in the household.

Several members of our community, particularly older residents, believe that the use of household water treatment technologies is a waste of time. They tell us that the only protection they need is God. (35 years old Female, WASH officer)

For some, water treatment practices were dissuaded by expectations of negligible health risks from untreated water.

... Most people don't even notice when they drink what you call 'unclean water' us farmers; we are a strong folk. (FGD 9, Female 50 years old)

The apparent mismatch between the expectations of the participants regarding water treatment technologies and the actual products appears to have affected the enthusiasm of the residents for some of the water treatment options.

I use a gravity water filter at home; I feel that the filter is too sluggish to provide my family with water at all times, to be frank. I wouldn't have invested in such a scheme, knowing what I know now. (FGD 6, Male 62 years old)

Long-standing customs such as herbal medications provided a sense of security for a few others.

... There is a reason why for centuries traditional herbs have been celebrated as a miracle for any disease ... I know people who have recovered from all sorts of diseases using just that. (FGD 14, Female 42 years old)

Individual behavior is affected by social norms. If other family members, peers, and community influencers see the behavior as beneficial, a person tends to meet their expectations. ${ }^{19}$ This was also true in the present study. A few of the participants discussed talking to others about the relevance of water treatment in the current study, and some of them indicated that their discussions inspired others to start using small-scale water treatment technologies. Participants also shared strong feelings about HEWs and the role that HEWs play in supporting them to buy and use materials for water treatment.

My neighbours say bad stuff about my water treatment, but HEWs come and compliment me on my water treatment. They (HEWs) tell me that my kids mustn't get sick with water. (FGD 2, Female 22 years old)

\section{Emotional Elements}

The desire of the participants to drink water without a detectable taste or smell was nearly universal in the present research. Despite differences in age, gender, and occupation, their preferences concerning taste, smell and clarity were consistent.

Wuha agar (Chlorine) treated water does not quench thirst; it has a heavy smell, as far as I'm concerned, it shouldn't smell. I don't know what the scent of clean water is or-I don't know, how do you explain the taste of water? You know, it hasn't got that taste. (FGD 7, Male 52 years old)

Similarly, rural residents who consume self-supplied water rely on water that comes from several meters below. This means that up to the point that it is drunk, the water stays cold. This experience has reinforced the perceptions of some rural residents on what makes water suitable for consumption; that is, water ought to be cold 
Boiled water's risk for consumer taste objections is very high. Many complain that it tastes flat. (25 years old Female, HEW)

The concerns about the lack of sincere motives by decision-makers while promoting household water treatment were repeatedly raised in several groups.

I like to emphasize that this mistrust is earned. For more than 30 years, this region has been struggling for more autonomy. Our government continues to use secret population control methods in marginalized, conflict-prone areas as a way of squashing long-term headaches. (FGD 2, Male 52 years old)

\section{Household-Level Factors}

Many participants expressed that the adoption and sustainable use of household water treatment technologies were influenced by the ability of households. The researchers attempted to understand what ability meant. Later, it became apparent that ability referred to competing household priorities and the availability of funds on hand. Most non-adopter households are from low-income households, the participants indicated.

To have properly boiled water for a regular drinking purpose requires affordable and sufficient fuel, and I don't think many individuals can do that, including myself. (FGD 11, Feale 38 years old)

Key informants did seem to agree with some aspects of the participants' characterizations.

In many of these communities, some of the main reasons given for no longer boiling water include "cannot buy enough fuel", "no stove," and "no appropriate pots".(32 years old Male, WASH officer)

In some cases, the role of women in decision-making or lack thereof appears to have influenced some households' adoption and/or sustainable use of water treatment.

There's nothing about treating water that I don't like, but my husband is the main decision-maker. (FGD 13, Female 38 years old)

Key informants also had strong views regarding the influence of intra-familial power on household water treatment practices.

In very traditional households where the married couple lives with the parents of the husband, the husband's mother has the ultimate authority over household expenses. So it's hard for the woman to implement smallscale water treatment technologies. (25 years old Female, HEW)

\section{Community-Level Factors}

For some, in the presence of social support, they viewed household water treatment as more doable.

We have health committees here. Following school hours, we meet at the local primary school and discuss weekly including on ways of treating water. (FGD 3, Male 38 years old)

Other participants, however, reported that some district health bureau workers seem to think, perhaps incorrectly, that the way to achieving the local administration's goals is by exhibiting an oppressive attitude towards residents. This feeling of the reported "control" over what members of the community should be part of seems to have affected the support of residents for water initiatives by the social groups, along with the education provided on water contamination.

\section{Environment and Context-Related Factors}

During the focus groups, the impact of easy access to treatment materials (chlorine, vessels, gasoline, wood for boiling, filters, etc.) on water treatment behavior was explored in detail. A handful of focus group participants indicated that Wuha Agar is often not accessible at local stores, and reported that they had at least one experience where only expired Wuha Agar was available at local stores.

Wuha agar is usually found cheap on market days (Tuesdays and Saturdays). But I have to walk down to the main road from my house, which takes about 30 minutes and then I travel by taxi to town. ... I do get them cheap there. (FGD 9, Female 42 years old)

Key informants indicated that small-scale household treatment technologies are not always accessible in more rural areas, restricting product access and, for some, adding transport costs to the purchase of such products.

They are encouraged to buy the treatment materials they can afford, but it is mostly available in large trading centers and not in the traditional villages where their water needs to be treated. (32 years old Male, HEW officer)

Informants also pointed out that as an incentive for attending on-going antenatal and postnatal checkups, the women 
in the community used to receive free bottles of chlorine solutions, soaps, and on-going behavior change messages about hygiene at clinic visits. As the visits came to a close, however, many noted that the mothers avoided enhancing the practice.

To encourage people to experiment with the product, experience its effects, and possibly allow the value of the product to be reassessed, the district management began offering free samples. This was also the tactic that many Nongovernmental organizations (NGOs) used, but many people I talk to say that made the community dependent on free hand-outs. (43 years old Male, WASH officer)

\section{Discussion}

The goal of this study was to explore the factors, experiences, attitudes, and beliefs among consumers of selfsupplied water in rural Ethiopia that influence household water treatment practices. The findings of this study will help to better understand the inhibitors and motivations influencing water treatment practices, develop more effective safe water behavioural interventions, and promote the diffusion of desired behaviours in similar environments. In this study, the participants discussed the cognitive predictors of household water treatment in detail. Knowledge of the causes of water-borne diseases, attitudes concerning the practice and product, low expectations of disease severity from untreated water, subjective norms, and support for treatment practices were identified as key cognitive influences at the individual level.

In any community, a disease must be regarded as a major public health concern to be effectively and sustainably managed. ${ }^{20}$ In the present study, a general lack of awareness about the need to treat water was described by many participants as a major barrier to household water treatment. This indicates that some community members were not well informed about water borne-illnesses. If the infected population does not view the disease as a significant public health issue, management and eventual elimination of the disease may be very difficult. ${ }^{21}$ There is therefore a clear need to supplement the knowledge of the community on water-borne illnesses to adequately raise awareness of water-borne diseases to a level that influences practices with a focus on behavioural change.

Another identified factor influencing household water treatment is linked to people's perceptions of water treatment needs and their vulnerability to diseases. While some respondents were able to express at least a basic understanding of how water can contain diarrheal diseasecausing germs, many reported being satisfied with their water source, even without treating it. Thus satisfaction with water sources was seen functioning as a disincentive to treatment. Evidence suggests that frequent educational messages have succeeded in increasing perceptions of the need to treat all drinking water and the acknowledgment of universal vulnerability to water-borne diseases. ${ }^{22}$

Similarly, the fact that many respondents stated that their primary motivation for trying water treatment, came from health professionals (particularly HEWs) and those they are closest to indicates that this form of personal contact is a significant influence on water treatment practices. In this context, it is important to mention a study conducted in Malawi that reported on the phenomenon of on-going social support. This, according to the finding of the study, is an important motivator for sustained water treatment behaviors. ${ }^{23}$

In the present study, it was found that people were more likely to adopt treatment technologies that were considered to be easy to access and use. Products deemed sluggish, for instance, emerged as examples of undesirable forms of water treatment technologies throughout FGDs. The introduction of technologies for water treatment is a task that requires intelligent and careful planning. This includes the engagement of the whole community, including in the design and delivery of products. ${ }^{24}$ Past research shows that communication is not only a medium for people to exchange messages, but also helps to develop social networks, contributing to consensus building. The health educator's ability to communicate his/her message impacts the community's preparedness to navigate such products. ${ }^{25}$

In addition to cognitive factors, aesthetic considerations were one of the most widely reported challenges to the adoption and continued use of water treatment. For many, the quality of drinking water was mainly judged by taste and odour. For instance, many expressed a dislike of the smell and taste of chlorine when using chlorine-based water treatment products. A recent WHO-funded study concluded that household-based chlorination was one of the most cost-beneficial choices for pursuing water goals. ${ }^{26}$ It should be noted that the chlorine taste and smell of chlorine-based water treatment products are not insurmountable obstacles to its use, particularly if people are encouraged to use it until they grow accustomed to the smell. ${ }^{27}$

In the study area, widespread civic disillusionment was seen as leading to the community's failure to sustain safe 
water practices. Participants raised concerns about the genuineness of the training they are given at different times. They perceived the training, services, and products they are offered as having ulterior motives. Community training programs should draw from a range of community-based stakeholders such as civil societies (CSOs). After all, CSOs at the grassroots level have a tremendous reputation as the voice of the people and, have the power to influence public opinions. ${ }^{28}$

Policy as a feature may affect adherence to safe practices. ${ }^{29}$ Given that a repeatedly documented obstacle to sustained use has been the lack of affordability of water treatment products, it seems likely that attempts to minimize the cost of such products or to keep the price as low as possible could increase their use. Evidence suggests that public subsidies have worked in other countries, ${ }^{30}$ despite the Ethiopian policy that stipulates zero subsidies for household water treatment products. This indicates that some flexibility concerning water subsidies might be needed in Ethiopia.

Virtually all women indicated that their husbands usually provide them with the money to buy household products. This result is in line with the findings of several other studies in Africa that reported that most women in the developing world do not have a voice equal to their partners in household spending, even if they are often the key implementers of household practices. ${ }^{18}$ Husband support seems likely to be important for most women to continue ongoing treatment practices, especially because when men manage family finances, husbands have to be sufficiently supportive of the product to pay for it. Cash access among primary caregivers is a critical component of consistent water treatment and in the context of endemic poverty, the lack of access to cash may constitute the only barrier to continued use for many. ${ }^{30}$

Community values are a collection of priorities representing one's feelings of connection to a community. To the degree that they associate with a specific group, individuals are more likely to accept a community's values as their own. ${ }^{31}$ Technology alone does not provide access to clean water, as social influences such as behavior and culture can operate in concert or even against the bestdesigned interventions. Policymakers also need to include communities in the design, implementation, and assessment of these initiatives. ${ }^{32}$ In the current study, it was found that even when they had access to water treatment options and despite improved awareness of the health consequences, some continued to drink contaminated water. Past reports also recognized that when water safety is a high priority for communities, they are more likely to have high levels of readiness or motivation to implement water treatment. ${ }^{33}$ Until such time comes where community values for treated water are high, local governments should work to establish a community engagement strategy focused on promoting dialogue with residents and public- and private-sector actors to create positive, longterm partnerships with communities.

Two other commonly cited obstacles to the trial and continued use of water treatment technologies, such as Wuha Agar and other chlorine-based water treatment products in the present study, are availability and access. Respondents often complained about the distance to stores that carry such products. Local governments should do a lot of outreach and distribution, as part of their water treatment policy, to expand the number of shops that carry treatment products. Similar social marketing efforts, in other nations, have been proven to be effective in increasing adoption and sustainable use. ${ }^{34}$

Studies have shown that giving away free samples causes a boost in product sales. If frequent sampling sessions are organized for a single product, there is also a snowball effect on sales. ${ }^{35}$ Programs focused primarily on delivering free samples, however, will only boost the actions of the community in the short term. Furthermore, delivering free samples risks the discontinuation of practices. ${ }^{36}$ For instance, if low-income families are given a "starter pack" of samples and are advised to purchase the products for the remaining period of treatment, they will not be able to afford the expense of the extension, contributing to treatment discontinuity.

This could be improved by implementing policies that encourage the use of locally available and inexpensive materials. Local governments can ensure product accessibility and affordability for sustained use at the household level by educating communities on the skills of constructing household water treatment technologies made from easily available materials. Most significantly, household water treatment is not about goods and technology, but about community mobilization, social marketing, and behavior change. Therefore, all stakeholders must have a rigorous communication strategy in place. ${ }^{37}$

\section{Limitations}

It should be noted that the analysis was carried out among a very homogeneous community with a similar ethnic composition. The results of the study can be generalized 
for a predominantly rural setting, except for factors linked to environmental circumstances, which may apply to comparable contextual locations. Also, individual-level factors and injunctive norms can be difficult to obtain from FGDs as individuals can provide more socially preferred responses than responses that represent their real experiences. Originally, our research was designed to compare water treatment technology users to nonusers. That being said, we found that this distinction was not as straightforward or as mutually exclusive as predicted, and because of seasonal variations, lack of resources, and other influences, many people's use of such items tends to oscillate over time. As a result, we did not have two different groups to compare and contrast responses.

\section{Conclusion}

This qualitative study contributes to our understanding of factors that facilitate and hinder the adoption and continued use of technologies for household water treatment. An important factor for the adoption and continued use of water treatment practices is regular interpersonal contact and social support from family, friends, and health workers. Future programs can benefit from such factors being emphasized. For example, beyond the model of providing ongoing safe water education by health extension workers, potential initiatives could be improved by community mobilization activities that include community leaders, women's groups, etc., in promoting water treatment at community engagements. Also, the results of the present study indicate that it could be beneficial to provide health extension staff with additional training to improve their ability to encourage community members across, a wide range of user types or levels of readiness, to treat their water, and also to provide social support for such behaviours.

\section{Future Research}

The results indicate that water treatment is more or less a fluid practice for many. It may be especially useful for program developers to be aware of such variability in practice when planning potential interventions and assessment studies. Program designers should be mindful of the variety of user categories that users may fall into (eg unwavering users, resource-dependent users, non-users, etc.), both to ensure that various types of users are considered and that on-going training messages are customized to suit each user.

\section{Abbreviations}

CLTSH, Community-Led Total Sanitation and Hygiene program; FGD, Focus group discussion; HEP, Health Extension Program; HEW, Health Extension Worker; IRB, Institutional Review Board; KII, Key informant interview; SDGs, Sustainable Development Goals; WASH, Water, Sanitation and Hygiene; WHO, World Health Organization.

\section{Data Sharing Statement}

All the data supporting the findings are included in this paper.

\section{Ethics Approval and Consent to Participate}

This study was approved and conducted per the principles of the Helsinki Declaration. Ethical clearance was obtained from Wachemo University College of Medicine and Health Science's Institutional Review Board. In advance of data collection, an approval letter was obtained from the Sidama Regional Health Bureau and Aleta Wondo District Health Office. Written informed consent was obtained from study participants. Participant informed consent included the publication of anonymized responses. Privacy and confidentiality of participants were guaranteed before, during, and after data collection.

\section{Acknowledgments}

Many thanks to all who were instrumental in the research process.

\section{Disclosure}

The author reports no conflicts of interest in this work.

\section{References}

1. Troeger CE, Khalil IA, Blacker BF, et al. Quantifying risks and interventions that have affected the burden of diarrhoea among children younger than 5 years: an analysis of the Global Burden of Disease Study 2017. Lancet Infect Dis. 2020;20:37-59. doi:10.1016/S14733099(19)30401-3

2. Soboksa NE, Hailu AB, Gari SR, Alemu BM. Water supply, sanitation and hygiene interventions and childhood diarrhea in Kersa and Omo Nada districts of Jimma Zone, Ethiopia: a comparative cross-sectional study. J Health Popul Nutr. 2019;38(1):45. doi:10.1186/s41043-0190205-1

3. Collaborators GS. Measuring the health-related sustainable development goals in 188 countries: a baseline analysis from the Global Burden of Disease Study 2015. Lancet. 2016;388(10053):1813-1850.

4. Alebel A, Tesema C, Temesgen B, Gebrie A, Petrucka P, Kibret GD. Prevalence and determinants of diarrhea among under-five children in Ethiopia: a systematic review and meta-analysis. PLoS One. 2018;13: e0199684. doi:10.1371/journal.pone.0199684 
5. Wolde AM, Jemal K, Woldearegay GM, Tullu KD. Quality and safety of municipal drinking water in Addis Ababa City, Ethiopia. Environ Health Prev Med. 2020;25(1):9. doi:10.1186/s12199-02000847-8

6. Ayalew M, Malcolm R, Okotto L-G, Pedley S, Chenoweth J, Mulugetta Y. The regulatory implications of the right to water: small-scale and independent water providers in Ethiopia and Kenya. OIDA Int J Sustain Dev. 2010;1:43-63.

7. Shine S, Muhamud S, Adanew S, Demelash A, Abate M. Prevalence and associated factors of diarrhea among under-five children in Debre Berhan town, Ethiopia 2018: a cross sectional study. BMC Infect Dis. 2020;20(1):174. doi:10.1186/s12879-020-4905-3

8. Alemayehu B, Ayele BT, Kloos H, Ambelu A. Individual and community-level risk factors in under-five children diarrhea among agro-ecological zones in southwestern Ethiopia. Int J Hyg Environ Health. 2020;224:113447. doi:10.1016/j.ijheh.2019.113447

9. Central Statistical Agency [Ethiopia] and Inner City Fund International. Ethiopia Demographic and Health Survey 2016. Addis Ababa, Ethiopia and Calverton, Maryland: Central Statistical Agency and ICF International; 2016.

10. MacAllister DJ, MacDonald AM, Kebede S, Godfrey S, Calow R. Comparative performance of rural water supplies during drought. Nat Commun. 2020;11(1):1099. doi:10.1038/s41467-020-14839-3

11. Berhanu A. Bacteriological and physicochemical quality of drinking water sources and household water handling practice among rural communities of Bona District, Sidama Zone-Zouthern, Ethiopia. Sci J Public Health. 2015;3:782. doi:10.11648/j.sjph.20150305.37

12. World Health Organization. World Health Statistics 2016: Monitoring Health for the SDGs Sustainable Development Goals. Geneva: World Health Organization; 2016.

13. Geremew A, Alemu B, Mellor J, Lantagne D, Alemayehu E, Gebrie G. Appropriate household water treatment methods in Ethiopia: household use and associated factors based on 2005, 2011, and 2016 EDHS data. Environ Health Prev Med. 2018;23:1-11. doi:10.1186/s12199-018-0737-9

14. Cha S, Kang D, Tuffuor B, Lee G, Cho J, Chung J. The effect of improved water supply on diarrhea prevalence of children under five in the Volta region of Ghana: a cluster-randomized controlled trial. Int J Environ Res Public Health. 2015;12:12127-12143. doi:10.3390/ ijerph121012127

15. Pickering AJ, Crider Y, Sultana S, Swarthout J, Goddard FG, Islam SA. Effect of in-line drinking water chlorination at the point of collection on child diarrhoea in urban Bangladesh: a double-blind, cluster-randomised controlled trial. Lancet Glob Health. 2019;7: e1247-e1256. doi:10.1016/S2214-109X(19)30315-8

16. Central Statistical Agency. Population projections for Ethiopia 2007-2037. Available from: www.csa.gov.et. Accessed March 25, 2020.

17. Assefa Y, Gelaw YA, Hill PS, Taye BW, Van Damme W. Community health extension program of Ethiopia, 2003-2018: successes and challenges toward universal coverage for primary healthcare services. Global Health. 2019;15(1):24. doi:10.1186/s12992-019-0470-1

18. Kayser G, Rao N, Jose R, Raj A. Water, sanitation and hygiene: measuring gender equality and empowerment. Bull World Health Organ. 2019;97:438-440. doi:10.2471/BLT.18.223305

19. Edberg M, Krieger L. Recontextualizing the social norms construct as applied to health promotion. SSM Popul Health. 2020;10:100560. doi:10.1016/j.ssmph.2020.100560

20. Prüss-Ustün A, Bartram J, Clasen T, Colford JM, Cumming O, Curtis V. Burden of disease from inadequate water, sanitation and hygiene in low-and middle-income settings: a retrospective analysis of data from 145 countries. Trop Med Int Health. 2014;19:894-905. doi:10.1111/tmi.12329
21. Ferrer R, Klein W. Risk perceptions and health behavior. Curr Opin Psychol. 2015;91.

22. D'Mello-Guyett L, Gallandat K, Van den Bergh R, et al. Prevention and control of cholera with household and community water, sanitation and hygiene (WASH) interventions: a scoping review of current international guidelines. PLoS One. 2020;15(1):e0226549. doi:10.1371/journal.pone. 0226549

23. Morse $\mathrm{T}$, Luwe $\mathrm{K}$, Lungu $\mathrm{K}$, et al. A transdisciplinary methodology for introducing SODIS to rural communities in Malawi - formative research findings. Integr Environ Assess Manag. 2020;16:871-884. doi:10.1002/ieam.4249

24. Majumdar S, Guha S, Parekh N. Technology and Innovation for Social Change: An Introduction. New Delhi: Springer; 2015:1-3.

25. Vermeir P, Vandijck D, Degroote S, et al. Communication in healthcare: a narrative review of the literature and practical recommendations. Int $J$ Clin Pract. 2015;69:1257-1267. doi:10.1111/ijcp. 12686

26. Botlagunta M, Bondili J, Mathi P. Water chlorination and its relevance to human health. Asian J Pharm Clin Res. 2015;8:20-24.

27. Solomon ET, Robele S, Kloos H, Mengistie B. Effect of household water treatment with chlorine on diarrhea among children under the age of five years in rural areas of Dire Dawa, eastern Ethiopia: a cluster randomized controlled trial. Infect Dis Poverty. 2020;9 (1):64. doi:10.1186/s40249-020-00680-9

28. Smith SL. Factoring civil society actors into health policy processes in low- and middle-income countries: a review of research articles, 2007-16. Health Policy Plan. 2019;34(1):67-77. doi:10.1093/heapol/ czy109

29. Gore R, Parker R. Analysing power and politics in health policies and systems. Glob Public Health. 2019;14(4):481-488. doi:10.1080/ 17441692.2019.1575446

30. Narzetti D, Marques R. Models of subsidies for water and sanitation services for vulnerable people in South American Countries: lessons for Brazil. Water. 2020;12:21. doi:10.3390/w12071976

31. Latif AS. The importance of understanding social and cultural norms in delivering quality health care-a personal experience commentary. Trop Med Infect Dis. 2020;5(1):22. doi:10.3390/tropicalmed5010022

32. Cyril S, Smith BJ, Possamai-Inesedy A, Renzaho AMN. Exploring the role of community engagement in improving the health of disadvantaged populations: a systematic review. Glob Health Action. 2015;8:29842. doi:10.3402/gha.v8.29842

33. Hove J, D'Ambruoso L, Mabetha D, et al. 'Water is life': developing community participation for clean water in rural South Africa. $B M J$ Global Health. 2019;4(3):e001377-e. doi:10.1136/bmjgh-2018001377

34. Evans D, Pattanayak S, Young S, Buszin J, Rai S, Bihm J. Social marketing of water and sanitation products: a systematic review of peer-reviewed literature. Soc Sci Med. 2014;110C:18-25. doi:10.1016/j.socscimed.2014.03.011

35. Wu L, Mattila A, Hanks L. Investigating the impact of surprise rewards on consumer responses. Int J Hosp Manag. 2015;50:27-35. doi:10.1016/j.ijhm.2015.07.004

36. Raizman R, MacNeil M, Maurice R. Is "free" really free? Ethical implications of short-term discounts and giveaways to hospitals. Healthcare Management Forum. 2020;33(2):90-92. doi:10.1177/ 0840470419891362

37. Gizaw Z, Addisu A. Evidence of households' water, sanitation, and hygiene (WASH) performance improvement following a WASH education program in rural Dembiya, Northwest Ethiopia. Environ Health Insights. 2020;14:1178630220903100. doi:10.1177/ 1178630220903100 


\section{Publish your work in this journal}

Risk Management and Healthcare Policy is an international, peerreviewed, open access journal focusing on all aspects of public health, policy, and preventative measures to promote good health and improve morbidity and mortality in the population. The journa welcomes submitted papers covering original research, basic science, clinical \& epidemiological studies, reviews and evaluations, guidelines, expert opinion and commentary, case reports and extended reports. The manuscript management system is completely online and includes a very quick and fair peer-review system, which is all easy to use. Visit http://www.dovepress.com/testimonials.php to read real quotes from published authors.

Submit your manuscript here: https://www.dovepress.com/risk-management-and-healthcare-policy-journal 